\title{
The Impact of the Preoperative Serum Albumin Level and Postoperative C-Reactive Protein Nadir on the Survival of Patients with Non-Metastatic Renal Cell Carcinoma with Vessel Thrombus after Nephrectomy
}

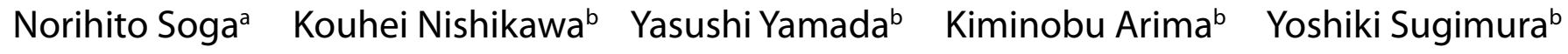 \\ aAichi Cancer Center, Department of Urology, Chikusa-ku, Nagoya; ${ }^{\mathrm{b} D i v i s i o n}$ of Nephro-Urologic Surgery and Andrology, \\ Mie University Graduate School of Medicine, Edobashi, Tsu , Japan
}

\section{Key Words}

Renal cell carcinoma $\cdot$ Tumor thrombus $\cdot$ Nephrectomy

\begin{abstract}
Purpose: To evaluate the predictors for survival in non-metastatic renal cell carcinoma (non-mRCC) associated with tumor thrombus following surgical resection. Patients and Methods: Between February 1983 and December 2009, a total of 40 patients with a diagnosis of non-mRCC ( 23 with pT3a pNOMO, 15 with pT3b pNOMO and 2 patients with pT3c pNOMO) were enrolled. Various preoperative and postoperative parameters were assessed as prognostic factors. Results: In the multivariate analysis, a low level of preoperative albumin less than $35 \mathrm{~g} / \mathrm{l}$ [hazard ratio (HR) 8.06] and high postoperative C-reactive protein (CRP): CRP nadir greater than $2 \mathrm{mg} / \mathrm{l}$ (HR 1.78) were identified significant risk factors for cause-specific survival. For the risk of progression-free survival, 3 factors proved to be significant independent predictors: a low preoperative albumin (HR 25.5), a high postoperative CRP nadir (HR 18.71) and low preoperative hemoglobin (HR 17.4). In 24 cases with the high preoperative CRP ( $>2$ $\mathrm{mg} / \mathrm{l})$, the progression-free survival rates in the low postoperative CRP nadir group achieved a significant better survival rate than the high CRP nadir group after nephrectomy $(p=$ 0.048). Conclusion: In non-mRCC with tumor thrombus after
\end{abstract}

\section{KARGER}

Fax +41613061234

E-Mail karger@karger.ch

www.karger.com
(C) 2011 S. Karger AG, Basel

1015-9770/11/0054-0190\$26.00/0

Accessible online at:

www.karger.com/cur surgical resection, a low preoperative albumin level and an elevated postoperative CRP nadir were significant independent predictors of survival.

Copyright $\odot 2011$ S. Karger AG, Basel

\section{Introduction}

Renal cell carcinoma (RCC) commonly expands into the major renal vessels to generate tumor thrombus. Indeed, thrombus in the renal vein or inferior vena cava (IVC) was detected in 4 to $15 \%$ of cases with RCC [1]. If a thrombectomy is accomplished during the complete nephrectomy resection, then the vessel thrombus cannot be recognized as a poor prognosis factor [2]. Based on the evidence in non-metastatic RCC (non-mRCC) with thrombus, aggressive surgical treatment was adapted as the optimal option for curable treatment [3, 4]. However, even though radical nephrectomy was accomplished as the initial treatment for non-mRCC with thrombus, cancer recurrence occurred in some cases and contributed to cancer-related death.

The adequate timing of adjuvant therapy for recurrence case does not exist. But, to establish the strategy of immediate starting of adjuvant therapy for recurrence 
cases, prognostic factors for survival are indispensable in order to select the high risk group and ensure close follow-up for that group. Recently several parameters have been demonstrated to be possible prognostic factors for survival in RCC with thrombus with or without metastasis [5]. However, since the survival predictor was not uncertain in restricted non-mRCC with thrombus after surgery, it is difficult to select the high risk group until the diagnosis of tumor progression.

To address these issues, we designed a retrospective case-control study to determine the survival predictors of non-mRCC with thrombus, especially in patients with pT3a, T3b and pT3c disease without metastasis and lymph node invasion. Multiple factors were evaluated as the candidates for survival prediction.

\section{Patients and Methods}

Between February 1983 and December 2009, suspicious kidney cancer was diagnosed in 394 patients who underwent radical nephrectomy at our Department of Urology. Forty cases of nonmRCC with thrombus meeting the following criteria were enrolled in this retrospective case-control study with informed consent:

- No prior treatment;

- Pathological diagnosis of kidney cancer. The histological tumor subtypes were classified by the Heidelberg classification [6];

- Stage pT3a, pT3b or pT3c with radical nephrectomy and thrombectomy (staging was determined according to the 2010 version of the American Joint Committee on cancer TNM) [7];

- No metastasis to other organs or lymph nodes (pN0, M0);

- Eastern Cooperative Oncology Group performance criteria of Grade 0 or 1 [8].

Chest computed tomography (CT), abdominal CT and bone scanning were employed preoperatively to screen for metastasis. A regional lymphadenectomy was performed together with a radical nephrectomy with metastasis to lymph node determined by pathological examination of the resected specimen.

All the cases were evaluated using serologic predictors that included preoperative platelet count and serum levels of hemoglobin, C-reactive protein (CRP), calcium and albumin. These predictors were also measured at least two times at monthly intervals after the operation.

Regarding the methods for measuring CRP, from 1983 to 2004 we used the immunoagglutination assay, while from 2005 to 2010 the latex agglutination assay was adopted. The companies supplying these products reported there is a high degree of correlation between these two assays.

The ionized calcium level was estimated by the formula: (total calcium level - 0.707) $\times($ albumin - 3.4) [9]. The nadir of the CRP level was estimated within two months after surgery, before starting of immunotherapy.

The decision to use immediate adjuvant immunotherapy with interferon- $\alpha$ at a dose of $600 \times 10^{4}$ IUs administered 3 times per week was made after discussion with the patient and receiving their informed consent. As there is no evidence of improved sur-

Predictor in Kidney Cancer after

Nephrectomy
Table 1. Baseline characteristics of patients

\begin{tabular}{|c|c|}
\hline Variables & \\
\hline \multicolumn{2}{|l|}{ Patient demography } \\
\hline Number & 40 \\
\hline Age, median ( range) & $65(35-81)$ \\
\hline$<60$ & 14 \\
\hline$>$ or $=60$ & 26 \\
\hline \multicolumn{2}{|l|}{ Performance status } \\
\hline 0 & 36 \\
\hline$\geq 1$ & 4 \\
\hline \multicolumn{2}{|l|}{ Gender } \\
\hline Male & 33 \\
\hline Female & 7 \\
\hline \multicolumn{2}{|l|}{ Laterality } \\
\hline Right & 18 \\
\hline Left & 22 \\
\hline Mean maximum diameter (range), $\mathrm{cm}$ & $8.0(1.2-17.0)$ \\
\hline \multicolumn{2}{|l|}{ Pathological stage } \\
\hline pT3a (thrombus within renal vein) & 23 \\
\hline pT3b (thrombus in IVC blow diaphragm) & 15 \\
\hline pT3c (thrombus in IVC over diaphragm) & 2 \\
\hline \multicolumn{2}{|l|}{ Histological cell type } \\
\hline Clear cell & 33 \\
\hline Non-clear cell & 7 \\
\hline \multicolumn{2}{|l|}{ Tumor grade } \\
\hline Grade $\leq 2$ & 34 \\
\hline Grade $\geq 3$ & 6 \\
\hline \multicolumn{2}{|l|}{ Immediate adjuvant immunotherapy } \\
\hline$(+)$ & 22 \\
\hline$(-)$ & 18 \\
\hline Median of after nephrectomy, month & $43.9(2-209)$ \\
\hline
\end{tabular}

vival with adjuvant immunotherapy for non-mRCC with thrombus after surgery, the best time to introduce such therapy is uncertain. Even though the patients were willing to receive adjuvant immunotherapy, all the cases had intermittent discharge from the hospital to recover from the surgical damage. The shortest interval between surgery and the start of adjuvant therapy was 2 months.

Our routine protocol to evaluate recurrence involved performing a CT scan every 3 months in the first year, every 4-6 months in the second year and every 6 months between the second and fifth years. CT scans were then undertaken annually up to 15 years. Recurrence and survival were estimated during the observation period.

\section{Statistical Analysis}

Survival curves were estimated using the Kaplan-Meier method. The determination of survival was between the date of nephrectomy and final date of follow-up including the death. Cause of death was determined from physician correspondence or the death certifications. The determination of progression was between the date of nephrectomy and detection date of local or metastatic nodule. 
Table 2. Univariate and multivariate results of Cox's proportional hazards model showing the relative risk of cause specific survival after surgery

\begin{tabular}{|c|c|c|c|c|c|c|}
\hline & \multicolumn{3}{|c|}{ Univariate model } & \multicolumn{3}{|c|}{ Multivariate model } \\
\hline & HR & $95 \% \mathrm{CI}$ & $\mathrm{p}$ & $\mathrm{HR}$ & $95 \% \mathrm{CI}$ & $\mathrm{p}$ \\
\hline Age $<60$ & 0.79 & $0.16-3.94$ & 0.80 & & & \\
\hline ECOG PS $\geq 1$ & 1.02 & $0.21-5.05$ & 0.98 & & & \\
\hline Tumor size $>7.0 \mathrm{~cm}$ & 0.83 & $0.15-4.54$ & 0.83 & & & \\
\hline thrombus in IVC & 0.62 & $0.12-3.01$ & 0.56 & & & \\
\hline Non-clear cell & 0.32 & $0.10-1.93$ & 0.32 & & & \\
\hline Pathological tumor grade $\geq 3$ & 2.78 & $0.32-23.84$ & 0.35 & & & \\
\hline Preoperative CRP > 10 mg/l & 3.86 & $0.70-21.28$ & 0.12 & & & \\
\hline Postoperative CRP > 2 mg/l & 9.1 & $1.06-78.57$ & 0.04 & 1.78 & $0.25-12.75$ & 0.048 \\
\hline Platelets $>300 \times 10^{3} / \mathrm{ml}$ & 5.31 & $0.96-29.33$ & 0.07 & & & \\
\hline Hemoglobin $<11.0 \mathrm{~g} / \mathrm{dl}$ & 3.84 & $0.70-21.08$ & 0.12 & & & \\
\hline Albumin $<35 \mathrm{~g} / 1$ & 14.96 & $1.73-129.08$ & 0.01 & 8.06 & $1.50-42.12$ & 0.013 \\
\hline Calculated calcium $>10 \mathrm{mg} / \mathrm{dl}$ & 4.79 & $0.95-24.19$ & 0.07 & & & \\
\hline Adjuvant immunotherapy & 50.5 & $0.06-80.2$ & 0.25 & & & \\
\hline
\end{tabular}

Cox's proportional hazards regression model using the backward elimination method for univariate and multivariate analysis was used to assess the baseline predictors for cause-specific survival (CSS) and progression-free survival (PFS). The comparisons of CSS and PFS depending on the CRP kinetics were analyzed using log-rank test.

The cut-off values for serologic data including preoperative platelet count and CRP, hemoglobin, and calculated calcium levels, were determined according to the univariate p-values. The normal range of the assay kits was used to define the cut-off levels for postoperative CRP and preoperative albumin.

A p-value less than 0.05 was considered statistically significant. Statistical analyses were performed using SPSS version 15 (SPSS Japan, Tokyo, Japan).

\section{Results}

\section{Patient Characteristics}

A total of 40 patients (23 with pT3a pNOM0, 15 with pT3b pNOM0 and 2 patients with pT3c pNOM0) were finally included and consisted of 33 males and 7 females. The median age of all patients was 65 years (range 3581 years) and the median tumor size was $8.0 \mathrm{~cm}$ (range $1.2-17.0 \mathrm{~cm}$ ). According to operation records, the median operation time was 305 minutes (range 150-920 minutes) and the median blood loss was $1,009 \mathrm{ml}$ (range $150-10,600 \mathrm{ml})$. Seventeen $(42 \%)$ patients received blood transfusion and albumin. Extracorporeal cardiopulmonary bypass and profound hypothermic circulatory arrest were needed in 2 cases with thrombus extending above the diaphragm. The maximum blood loss $(10,600$ $\mathrm{ml}$ ) occcured due to the injury of inferior vena cava, under the extracorporeal cardiopulmonary bypass associated with profound hypothermic circulatory arrest.

Histological examination confirmed 33 clear cell carcinomas and 7 non-clear cell carcinomas, consisted of 3 with chromophobe type, 3 with papillary type and 1 with cystic type. Immunotherapy was undertaken in 22 cases $(55 \%)$ (table 1).

\section{Univariate and Multivariate Evaluation}

The analysis using a Cox's proportional hazards regression model was performed using age, performance status, tumor size, pathological result, pre- or post-operative laboratory data and the use or absence of immunotherapy as variables.

The univariate analysis indicated that the high postoperative CRP nadir (>2 mg/l) and the low preoperative albumin level $(<35 \mathrm{~g} / \mathrm{l})$ were significant risk factors for both PFS and CSS. A high preoperative CRP level ( $>10$ $\mathrm{mg} / \mathrm{l})$ tended to be a predictor for PFS $(\mathrm{p}<0.05)$ and but was not statistically significant for CSS $(p=0.12)$.

Multivariate analysis indicated that a low level of preoperative albumin less than $35 \mathrm{~g} / 1$ [hazard ratio (HR) 8.06] and high CRP nadir greater than $2 \mathrm{mg} / \mathrm{l}$ (HR 1.78) were identified significant risk factors for CSS. For the risk of PFS, 3 factors proved to be significant indepen- 
Table 3. Univariate and multivariate results of Cox's proportional hazards model showing the relative risk of progression-free survival after surgery

\begin{tabular}{|c|c|c|c|c|c|c|}
\hline & \multicolumn{3}{|c|}{ Univariate model } & \multicolumn{3}{|c|}{ Multivariate model } \\
\hline & HR & $95 \%$ CI & $\mathrm{p}$ & $\mathrm{HR}$ & $95 \% \mathrm{CI}$ & $\mathrm{p}$ \\
\hline Age $<60$ & 1.65 & $0.41-6.66$ & 0.48 & & & \\
\hline ECOG PS $\geq 1$ & 0.66 & $0.17-2.54$ & 0.55 & & & \\
\hline Tumor size $>7.0 \mathrm{~cm}$ & 0.83 & $0.20-3.41$ & 0.80 & & & \\
\hline Thrombus in IVC & 0.83 & $0.23-3.10$ & 0.78 & & & \\
\hline Non-clear cell & 0.4 & $0.10-1.70$ & 0.23 & & & \\
\hline Pathological tumor grade $\geq 3$ & 4.42 & $0.55-35.20$ & 0.16 & & & \\
\hline Preoperative CRP > 10mg/l & 4.14 & $1.02-16.78$ & 0.047 & & & \\
\hline Postoperative CRP > 2mg/l & 7.06 & $1.44-34.51$ & 0.01 & 18.71 & $1.60-208.9$ & 0.017 \\
\hline Platelets $>300 \times 10^{3} / \mathrm{ml}$ & 2.88 & $0.68-12.11$ & 0.15 & & & \\
\hline Hemoglobin $<11.0 \mathrm{~g} / \mathrm{dl}$ & 1.89 & $0.50-7.09$ & 0.35 & 17.40 & $1.21-250.39$ & 0.036 \\
\hline Albumin $<35 \mathrm{~g} / 1$ & 7.55 & $1.87-30.42$ & 0.004 & 25.50 & $2.33-278.57$ & 0.008 \\
\hline Calculated calcium $>10 \mathrm{mg} / \mathrm{dl}$ & 3.42 & $0.76-15.39$ & 0.11 & & & \\
\hline Adjuvant immunotherapy & 51.1 & $0.22-78.01$ & 0.16 & & & \\
\hline
\end{tabular}

dent predictors: a low preoperative albumin (HR 25.5), a high postoperative CRP nadir (HR 18.71) and a low preoperative hemoglobin (HR 17.4) (table 2 and 3).

\section{Survival}

The median observation period was 43.9 months and the overall survival rate after surgery was 75.3 ( 5 years), 68.3 (10 years) and $54.4 \%$ (15 years). Six patients died secondary to cancer-related reasons. The 5-, 10- and 15year CSS rates were all 77.3\%. Progressive disease was demonstrated in 9 cases with the metastatic sites comprising the lungs in 6 cases, bones in 2 cases and the local IVC in 1 case. The PFS rate after resection was 76.3 (5 years), 70.9 (10 years) and 57\% (15 years).

To evaluate the CRP kinetics, 24 cases with the high preoperative CRP ( $>2 \mathrm{mg} / \mathrm{l}$ ) were collected for additional analysis. In 6 of the cases, postoperative CRP levels had normalized. We compared the 2 groups based on CSS and PFS. The groups consisted of cases with postoperative normalized CRP (low CRP nadir group, $\mathrm{n}=6$ ) and postoperative unnormalized CRP (high CRP nadir group, $\mathrm{n}=18$ ).

The 5- and 10-year CSS rates in the low CRP nadir group were all $100 \%$. On the other hand the 5- and 10year CSS rates in the high CRP nadir group were both $60.0 \%$. The CSS rates showed the low CRP nadir group tended to be a better survival rate than the high CRP nadir group $(\mathrm{p}=0.152)$.

Predictor in Kidney Cancer after Nephrectomy
The 5- and 10-year PFS rates in the low CRP nadir group were all $100 \%$. In contrast, the 5- and 10-year PFS rates in the high CRP nadir group were 57.6 and $46.1 \%$, respectively. The PFS rates in the low CRP nadir group achieved a significant better survival rate than the high CRP nadir group $(p=0.048)$ (fig. 1 ).

\section{Discussion}

Even though the RCC cases associated with tumor thrombus were diagnosed, a good prognosis will only be accomplished when the surgical removal of vessel thrombus was effectively undertaken [10]. Also, involvement of the renal vein or sub-diaphragmatic IVC does not affect prognosis [2]. Therefore, cases with tumor thrombus may be found at a non-metastatic stage and extensive surgical treatment is commonly employed as the best initial management and a potentially curative treatment option [3, 4].

In fact, in cases where the renal tumor involved only the renal vein without any other adverse prognostic factor, the survival expectancy is favorable, since the CSS rate was $83 \%$ at 5 years and $71 \%$ at 10 years after surgical resection [2], which was comparable to the outcome in our study where we observed 5- and 10-year CSS rates of $77.3 \%$. However, the unfortunate development of

Curr Urol 2011;5:190-195 
metastatic disease occurred in some cases after surgery and these high risk cases should be offered additional treatment.

In order to select high risk cases, the probability of recurrence and the optimal prognostic factors are required. In the cases of RCC with tumor thrombus, including cases with metastatic disease, the importance of prognostic factors including CRP and lymph node metastasis was demonstrated [5]. However, the prognostic factors in non-mRCC associated with tumor thrombus are not well elucidated.

Our data indicate that the low preoperative level of albumin and high postoperative CRP nadir were the independent risk factors for both CSS and PFS, whilst the low hemoglobin level was a significant independent predictor for the risk of PFS in non-mRCC with thrombus after surgery.

The systemic inflammatory response is associated with hypoalbuminemia and an elevated CRP [11]. Previous work indicated that the inflammation-based prognostic score (Glasgow prognostic score) consisting of these two parameters predicted survival in mRCC [12]. Although the pathogenic nature of the association between the systemic inflammatory response and cancer-related survival was uncertain, the presence of an inflammatory response may influence the tolerance and compliance with active treatment [13]. In addition, the inflammatory response may produce progressive nutritional and functional decline that adversely affects prognosis [12]. If cases of non-mRCC with thrombus exhibited a severe inflammatory response associated with poor performance status, then the operation may not be adopted in view of the reduced level of tolerance for invasive surgery. On the contrary, if the cases in our study were evaluated to have a relatively good performance status ( 0 or 1$)$ without evidence of a severe inflammatory response, then a radical resection was adopted. Therefore, since the candidates for surgery tend to maintain their generally good condition, it was difficult to distinguish any differences between cases according to the systematic inflammatory response. In fact, only preoperative hypoalbuminemia, but not the preoperative CRP level, might be a significant predictor of the recurrence risk in cases of non-mRCC with tumor thrombus.

In general, almost all previous reports focused on the relation of the preoperative CRP level to survival [14, 15]. However, several studies estimated postoperative CRP level related to survival, in mRCC $[16,17]$ or curative RCC [18] after nephrectomy. In this study the postoperative CRP nadir was a significant prognostic factor

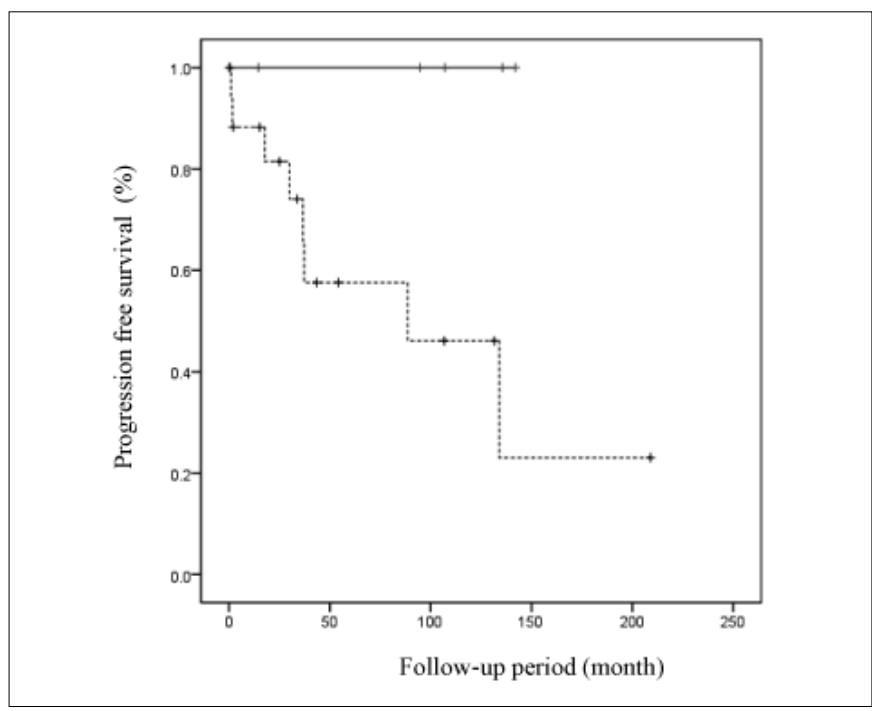

Fig. 1. Kaplan Meier curves showing progression-free survival in the low CRP nadir group (solid line) and high CRP nadir group (dotted line) (Log rank test, $\mathrm{p}=0.048)$.

for CSS and PFS. In addition, in the cases with the high preoperative CRP, the CRP kinetics affected the progression after surgery (fig. 1).

The prognostic effect of the post-treatment CRP level raises the hypothetical possibility of targeting later treatment. This hypothesis was supported by the work of Saito et al. [19] who reported that a normalized CRP level during the treatment of $\mathrm{mRCC}$ was a significant prognostic factor. We therefore hypothesized that the nadir of the CRP level might potentially reflect the presence or absence of micro-metastatic disease and thus predict the risk of future recurrent disease. In other words, the presence of residual micro-metastasis following a completed resection might induce an inflammatory response that affects the fall of the serum CRP level. As a result, a raised level of the CRP nadir may indicate a high risk of recurrence.

In conclusion, preoperative hypoalbuminemia and an elevated postoperative CRP level might represent useful predictors of prognosis after surgical treatment for nonmRCC associated with tumor thrombus. Thus high risk cases, selected by these predictive parameters, require a careful follow-up schedule in order to assess the optimal timing of any adjuvant therapy including molecular targeting therapy to minimize the risk of progressive disease. 


\section{References}

1 Marshall FF, Dietrick DD, Baumgartner WA, Reitz BA: Surgical management of renal cell carcinoma with intracaval neoplastic extension above the hepatic veins. J Urol 1988; 139:1166-1172.

- 2 Ficarra V, Righetti R, D'Amico A, Rubilotta E, Novella G, Malossini G, Mobilio G: Renal vein and vena cava involvement does not affect prognosis in patients with renal cell carcinoma. Oncology 2001;61:10-15.

-3 Bissada NK, Yakout HH, Babanouri A, Elsalamony T, Fahmy W, Gunham M, Hull GW, Chaudhary UB: Long-term experience with management of renal cell carcinoma involving the inferior vena cava. Urology 2003;61:89-92.

4 Parekh DJ, Cookson MS, Chapman W, Harrell F Jr, Wells N, Chang SS, Smith JA Jr: Renal cell carcinoma with renal vein and inferior vena caval involvement: clinicopathological features, surgical techniques and outcomes. J Urol 2005;173:1897-1902.

5 Tanaka M, Fujimoto K, Okajima E, Tanaka N, Yoshida K, Hirao Y: Prognostic factors of renal cell carcinoma with extension into inferior vena cava. Int J Urol 2008;15:394-398.

6 Kovacs G, Akhtar M, Beckwith BJ, Bugert P, Cooper CS, Delahunt B, Eble JN, Fleming S, Ljungberg B, Medeiros LJ, Moch H, Reuter VE, Ritz E, Roos G, Schmidt D, Srigley JR, Storkel S, van den Berg E, Zbar B: The Heidelberg classification of renal cell tumours. $\mathbf{J}$ Pathol 1997;183:131-133

7 Edge SB, Byrd DR, Compton CC, Fritz AG: AJCC Cancer Staging Manual, ed 7. New York, Springer-Verlag, 2010.
-8 Oken MM, Creech R H, Tormey DC, Horton J, Davis TE, McFadden ET, Carbone PP: Toxicity and response criteria of the Eastern Cooperative Oncology Group. Am J Clin Oncol 1982;5:649-655.

-9 Motzer RJ, Bacik J, Schwartz LH, Reuter V, Russo P, Marion S, Mazumdar M: Prognostic factors for survival in previously treated patients with metastatic renal cell carcinoma. J Clin Oncol 2004;22:454-463.

10 Samma S, Yoshida K, Ozono S, Ohara S, Hayashi Y, Tabata S, Uemura H, Iwai A, Hirayama A, Hirao Y: Tumor thrombus and microvascular invasion as prognostic factors in renal cell carcinoma. Jpn J Clin Oncol 1991; 21:340-345.

11 McMillan DC, Elahi MM, Sattar N, Angerson WJ, Johnstone J, McArdle CS: Measurement of the systemic inflammatory response predicts cancer-specific and non-cancer survival in patients with cancer. Nutr Cancer 2001;41:64-69.

12 Ramsey S, Lamb GW, Aitchison M, Graham J, McMillan DC: Evaluation of an inflammation-based prognostic score in patients with metastatic renal cancer. Cancer 2007;109: 205-212.

13 Forrest LM, McMillan DC, McArdle CS, Angerson WJ, Dunlop DJ: Evaluation of cumulative prognostic scores based on the systemic inflammatory response in patients with inoperable non-small-cell lung cancer. $\mathrm{Br} \mathrm{J}$ Cancer 2003;89:1028-1030.
14 Lamb GW, McMillan DC, Ramsey S, Aitchison $\mathrm{M}$ : The relationship between the preoperative systemic inflammatory response and cancer-specific survival in patients undergoing potentially curative resection for renal clear cell cancer. Br J Cancer 2006;94:781784.

15 Komai Y, Saito K, Sakai K, Morimoto S: Increased preoperative serum C-reactive protein level predicts a poor prognosis in patients with localized renal cell carcinoma. BJU Int 2007;99:77-80.

16 Fujikawa K, Matsui Y, Oka H, Fukuzawa S, Takeuchi H: Serum C-reactive protein level and the impact of cytoreductive surgery in patients with metastatic renal cell carcinoma. J Urol 1999;162:1934-1937.

17 Tatokoro M, Saito K, Iimura Y, Fujii Y, Kawakami S, Kihara K: Prognostic impact of postoperative C-reactive protein level in patients with metastatic renal cell carcinoma undergoing cytoreductive nephrectomy. J Urol 2008;180:515-519.

18 Johnson TV, Abbasi A, Owen-Smith A, Young AN, Kucuk O, Harris WB, Osunkoya AO, Ogan K, Pattaras J, Nieh PT, Marshall FF, Master VA: Postoperative better than preoperative $\mathrm{C}$-reactive protein at predicting outcome after potentially curative nephrectomy for renal cell carcinoma. Urology 2010; 76:766e1-5.

19 Saito K, Tatokoro M, Fujii Y, Iimura Y, Koga F, Kawakami S, Kihara K: Impact of $\mathrm{C}$-reactive protein kinetics on survival of patients with metastatic renal cell carcinoma. Eur Urol 2009;55:1145-1154. 